\title{
Research Exemption/Experimental Use in the European Union: Patents Do Not Block the Progress of Science
}

\author{
Hans-Rainer Jaenichen and Johann Pitz \\ Vossius \& Partner, 81675 München, Germany \\ Correspondence: jaenichen@vossiusandpartner.com; pitz@vossiusandpartner.com
}

In the public debate about patents, specifically in the area of biotechnology, the position has been taken that patents block the progress of science. As we demonstrate in this review, this is not the case in the European Union (EU). The national patent acts of the EU member states define research and experimental use exemptions from patent infringement that allow sufficient room for research activities to promote innovation. This review provides a comparative overview of the legal requirements and the extent and limitations of experimental use exemptions, including the so-called Bolar provision, in Germany, the United Kingdom, France, Spain, Italy, and The Netherlands. The legal framework in the respective countries is illustrated with reference to practical examples concerning tests on patentprotected genetic targets and antibodies. Specific questions concerning the use of patentprotected research tools, the outsourcing of research activities, and the use of preparatory and supplying acts for experimental purposes that are necessary for conducting experiments are covered.

In the public debate about patents, specifically in the area of biotechnology, the position has been taken that patents block the progress of science. As we demonstrate in this review, this is not the case. Patents are the proper tool to motivate innovation. Not only do they provide the chance for entrepreneurs and innovative industries to generate return of investment and, at times, profit, but they also allow the scientific community to further innovative research by full disclosure of new technical contributionsunless that research actually uses the patented invention as a tool without intending to fur- ther develop it. In the European Union (EU), this balance is achieved by the member states' national patent acts, which define research and experimental use exemptions from patent infringement. In addition, there is the so-called Bolar exemption, which allows studies and trials that are required for the purpose of regulatory approval of medicinal products.

This legal framework is illustrated with reference to two practical examples. Example A is an exemplary patent on a genetic target and its use for diagnostic purposes. The hypothetical claims are:

Editors: Salim Mamajiwalla and Rochelle Seide

Additional Perspectives on Intellectual Property in Molecular Medicine available at www.perspectivesinmedicine.org

Copyright (C) 2015 Cold Spring Harbor Laboratory Press; all rights reserved; doi: 10.1101/cshperspect.a020941

Cite this article as Cold Spring Harb Perspect Med 2015;5:a020941 
H.-R. Jaenichen and J. Pitz

1. a DNA fragment encoding human proliferase $\mathrm{H}$, said proliferase $\mathrm{H}$ having the amino acid sequence set out in SEQ ID NO: $2{ }^{1}$

2. the DNA fragment of claim 1, which comprises in the proliferase $\mathrm{H}$-encoding sequence a frameshift mutation being indicative of a predisposition to abnormal hair growth;

3. a method for diagnosing a predisposition for abnormal hair growth in a human subject, which comprises determining in a tissue sample of said subject whether there is a germline frameshift mutation in the sequence of SEQ ID NO: 2 encoding proliferase $H$, said frameshift mutation being indicative of a predisposition to said abnormal hair growth.

Dr. Curly has a research group in a German hospital and is interested in investigating whether frameshift mutations in the proliferase $\mathrm{H}$ gene are also indicative of a predisposition to eyebrow cancer. He is planning to register a medicinal product with the U.S. Food and Drug Administration (FDA) and to conduct clinical trials in case his experiments confirm that causal relationship. His colleague Dr. Straight offers patients in a German hospital genetic tests for predisposition to abnormal hair growth and claims that this is done in context with his research. Are they exempted from patent infringement under EU provisions?

Example B is an exemplary patent for an antibody and medical uses thereof. The hypothetical claims are:

1. anti-CD390 antibody 1 having the VH polypeptide of SEQ ID NO: 1 and the VL polypeptide of SEQ ID NO: 2;

2. a pharmaceutical composition comprising the antibody of claim 1, optionally in combination with a pharmaceutically acceptable carrier;

\footnotetext{
${ }^{1}$ DNA molecules, including genomic DNA and cDNA, have been and are considered patentable in the European Patent Office; see, for example, T 1213/05 (Breast and ovarian cancer/UNIVERSITY OF UTAH), T 18/09 (Neutrokine/ HUMAN GENOME SCIENCES), and T 80/05 (Method of diagnosis/UNIVERSITY OF UTAH).
}

3. an anti-CD390 antibody having the $\mathrm{VH}$ polypeptide of SEQ ID NO: 1 and the VL polypeptide of SEQ ID NO: 2 for use in a method of treating malignant hair growth.

Dr. Specific, head of immunology of a German research center, is considering starting a project aimed at investigating whether said antibody 1 can also be used for treating renal failure. In view of Dr. Specific's intention to bring a medicinal product to the European market, the project will also encompass preclinical pilot studies concerning efficacy in the human body. Dr. Specific intends to have antibody 1 produced by supplier Ab Inc. because he himself does not have the required production knowhow. His colleague Dr. Affinity uses antibody 1 as a tool in his research for monitoring the CD390 surface antigen during hair follicle morphogenesis. Are they exempted from patent infringement under EU provisions?

\section{THE SITUATION IN GERMANY}

\section{Research Privilege \\ Legal Basis}

According to the $\$ 11$ No. 2 German Patent Act (GPA), the effects of a patent shall not extend to "acts done for experimental purposes relating to the subject matter of the patented invention." The research exemption was first introduced into the law in 1981 and has been interpreted to provide for a broad range of allowed uses, for example, producing, importing, possessing, and using the protected product or process as a subject of research. Relevant for determining the scope and limitations of the so-called experimental use exemption are the German Federal Court of Justice (FCJ) decisions of July 11, 1995 (Klinische Versuche I) (Clinical Trials $I)^{2}$ and April 17, 1997 (Klinische Versuche II) (Clinical Trials II). ${ }^{3}$ The criteria formulated in these decisions not only apply to clinical trials, but are also generally applicable to nonclinical research.

\footnotetext{
${ }^{2}$ BGH NJW 1996, 782.
}

${ }^{3}$ BGH NJW 1997, 3092. 


\section{Requirements}

Research on the Subject Matter. The research exemption will only apply if the research is directed to the patented subject matter as such. It does not cover research with a patent-protected process or product to obtain information about other products or processes; that is, where the patented subject matter is merely a tool for carrying out research on other products and processes, $\$ 11$ No. 2 GPA does not apply. For example, the use of patented test procedures for their intended purpose, that is, for performing experiments disclosed or claimed, is not exempted from patent protection because in such a case the patented test procedure itself would not be studied. Rather, it is simply used as a means for performing the disclosed or claimed experiment. Similarly, if the patent in question relates to a platform technology such as a drug delivery system, but the experiments are aimed at looking at the mechanism of action of an active ingredient delivered using that system, the exemption would likely not apply. In this case, the purpose of the experiments is to use the platform technology as a tool to investigate the activity of the active ingredient and not to find out something new about the platform technology per se. Therefore, there would not be a real and direct connection with the subject matter of the relevant invention. Conversely, if the patent were for a screening assay, the initial stages in the development of a screening assay for research purposes would fall within the exemption. However, using such a screening assay to identify new drug candidates would not relate to testing the invention and so would fall outside the exemption.

Gaining New Knowledge. According to the case law of the German FCJ, a privileged experiment is a planned action for obtaining information about the subject matter of the patented invention. In this respect, the demarcation between already-known information and new findings is important. The research exemption is evident if an experiment is directed to resolving any questions and/or obtaining further information about the subject matter of the patented invention.
Without mentioning concrete criteria to differentiate between privileged research and infringing use, the German FCJ in its decisions Clinical Trials I and II refers to a case-by-case evaluation where both the form of the tested substance and above all the intentions of the persons and companies involved must also be taken into account.

In line with earlier case law, ${ }^{4}$ experiments are permissible that relate to the constitution of the patented substance, for example, experiments for investigating its composition, producibility, technical usability, and effects. Also allowed are experiments for testing the functionality of the patented invention. According to the German FCJ decision Clinical Trials I, this exemption includes using the subject matter of the invention for finding new, previously unknown applications or indications and-according to the decision Clinical Trials II-experiments for obtaining information about the properties and effects of the patented substance within the known pharmaceutical indications. Preclinical and/or clinical trials performed on a new chemical entity that is not known to have medical utility in order to find out whether it does have medical utility also fall within the existing experimental use exemption.

Based on the above principles, Dr. Curly's research activities are covered by the research privilege. As clarified in the German FCJ decision Clinical Trials $I$, the patent-protected substance can be used as an object of research to find new knowledge about properties that are not yet explored. Because Dr. Curly has set up experiments to find out whether the proliferase $\mathrm{H}$ gene is indicative of predisposition to eyebrow cancer, he can rely on the experimental use exemption. The same is true with the research activities of Dr. Specific, who is using the patent-protected antibody 1 to investigate its unknown usability for treating renal failure.

\footnotetext{
${ }^{4}$ German FCJ decision of June 2, 1981, GRUR 1981, 734 (Erythronolid); LG Berlin decision of September 25, 1984, GRUR 1985, 375 (Klinischer Test); District Court Düsseldorf decisions of December 4, 1984, and March 5, 1985, GRUR Int. 1986, 807 (Feldversuche); and German FCJ decision of February 21, 1989, GRUR 1990, 997 (Ethofumesat).
} 
H.-R. Jaenichen and J. Pitz

\section{Reach and Limitations}

Economic Background. The goal of the experimental uses is not relevant as long as the experiments are conducted to gain new knowledge about the patented invention. It is not relevant whether the experiments are conducted strictly for research purposes or also with the aim of commercial exploitation. Therefore, it is permissible to conduct experiments with commercial purposes.

The research exemption, however, does not apply in cases where the activities are done solely for the purpose of generating revenues or clarifying commercial factors, such as market needs, price acceptability, and marketing options. ${ }^{5}$ Accordingly, it appears as if the offer of genetic tests to patients by Dr. Straight is not covered by the privilege. The research exemption may, however, even apply in cases in which the experimental use acts are primarily directed to realizing commercial purposes and in which further technical and/or scientific knowledge is acquired and obtained as a side effect only. To rely on the experimental use privilege, Dr. Straight would have to show that he is collecting and observing specific data from patients during the test with the purpose of investigating unknown properties and/or functions of the patent-protected DNA fragment and/or the patent-protected method.

Limitation of Amounts. The so-called argument of scale, developed by the German FCJ in its decision Clinical Trials II, provides a clear criterion of demarcation from an abuse of the experimental use exemption. If experiments are performed on a scale no longer justifiable as having an experimental purpose, they are not permissible experimental use acts within the meaning of $\$ 11$ No. 2 GPA. Thus, the case law of the German FCJ prevents large-scale test series from flooding the market with patented substances so as to block the patent owner's original products. Patent-protected products may therefore only be generated and used to an extent that is necessary to achieve the purpose of the desired research. Stocking of patent-protected products for the purpose of future

${ }^{5}$ Cf. Mes, $\$ 11$ GPA, marginal no. 7. marketing after the expiry of patent protection is not allowed.

Furthermore, abuse of the experimental use exemption by experiments carried out with the purpose of disturbing the inventor's distribution of his or her product for an extended period of time is to be prevented. In this case, the experiments would only serve as a means for obtaining a competitive advantage. In practice, however, it will be difficult to prove that experiments were done with the intention of causing a disturbance when there actually exists a current research purpose. For example, in Example $\mathrm{A}$, the experimental use exemption in favor of Dr. Straight would also be questionable in view of the "argument of scale." Whereas experiments to verify the functionality of the protected DNA fragment as described in the patent would be allowed, an unlimited offer to all patients who are interested in testing their predisposition to abnormal hair growth is not permitted.

Research Tools. Patented research tools used in research not relating to the tool as such but to other subject matter are frequently required for studies and experiments. They involve, for example, laboratory equipment, chemical reagents, cell lines, antibodies, or the use of patented receptors for application in screening processes. In Example B, Dr. Affinity uses antibody 1 as a tool in his research for monitoring the CD390 surface antigen during hair follicle morphogenesis. In this case, the antibody as such is not the object of study and therefore does not fall under the research exemption of $\$ 11$ No. 2 GPA.

Because the patent protection of research tools does not extend to the information generated therewith, no cease-and-desist claim exists for the use of the obtained data in further technical developments, even if the use of the tool was not authorized. ${ }^{6}$

Research by Order. The question of whether research work can be outsourced to contractors has been and remains controversial among

${ }^{6}$ Cf. von Meibom/vom Feld, Durchgriffsansprüche (ReachThrough-Ansprüche) bei Patenten für Forschungszwecke, Festschrift für Kurt Bartenbach (2005), pp. 385, 390 et seqq. 
scholars. ${ }^{7}$ However, the prevailing opinion in the literature is that, in principle, it should be possible to outsource research to contractors as long as the work remains focused on the subject matter of the patent. Therefore, it is advisable to specifically define the purpose of the contractual work in the respective agreements with the contractors. This is because the research exemption only extends to contractors who are aware that their work is performed in the context of privileged research.

Preparatory Acts. It is still not clear how far the experimental use exemption covers preparatory and supplying acts that are necessary for conducting any privileged experiment. In the pharmaceutical field, for example, this includes the development and preparation of antibodies for diverse diagnostic purposes, the development and production of tools for carrying out the tests required for obtaining a marketing authorization, and the production of test kits in accordance with the approval criteria laid down in pharmaceutical law. Here, a distinction must be made between, on the one hand, acts of the company subject to the experimental use exemption and, on the other hand, a third party's supplying acts, such as the preparation and distribution of the patented object of study. Properly framed, the experimental use exemption should cover the production of the patented object by a company itself enjoying the right to conduct experiments under the experimental use exemption, provided that the form and volume of said production is exclusively directed to experimental purposes. As Dr. Curly's research activities with the patent-protected substance are allowed in Example A, he is also free to produce the substance to be used in his tests. This approach prevents the experimental use exemption from being undermined in cases in which the object of study cannot readily be purchased and the patent owner refuses to give his or her consent to the use thereof.

In contrast, the question of whether a third party would fall under the experimental use

${ }^{7}$ See, for example, Benkard/Scharen, GPA, 10th edition 2006, \$11, marginal no. 8. exemption, where contracted to prepare and distribute the object of study for privileged experiments (but not to perform the experiments themselves), is more difficult to answer. In patent literature, the view is occasionally held that the experimental use exemption covers such supplying acts ${ }^{8}$ provided that the supplier knows that the recipient intends to use the received products/means only for performing research on the protected subject matter.

The wording of $\$ 11$ No. 2 GPA however, also suggests that acts done for experimental purposes are only privileged as long as they are carried out for performing the experiment. ${ }^{9}$ The fact that the offer and sale of patent-protected test substances by the above third party are not acts done for experimental purposes is an argument against extending the privilege to cover them. This view is supported by $\$ \$ 10(1)$ and (3) GPA, which provide that the supply of material constitutes an act of indirect infringement even if the recipient might be privileged according to the research exemption.

For example, the District Court Düsseldorf denied the experimental use exemption for suppliers of test substances in its judgment dated July 3, 2012. ${ }^{10}$ According to the court's reasoning, the experimental use privilege can only cover such third-party activities if the suppliers can be considered as coparticipants of the research with an individualized interest in gaining further knowledge regarding the patent-protected substance. Based on this ruling, the supplier Ab Inc. in Example B would not be allowed to produce the patent-protected antibody 1 .

In practice, it would not be appropriate to completely disregard the experimental use exemption for third parties' supplying acts. For example, in cases in which the privileged com-

\footnotetext{
${ }^{8} \mathrm{Cf}$. Fähndrich/Tilmann, Patentbenutzende Bereitstellungshandlungen bei Versuchen, GRUR 2001, 901.

${ }^{9}$ Cf. Benkard/Bruch hausen, $\$ 11$ GPA, marginal no. 6, who in this connection refer to an early decision of the Supreme Court of the German Reich according to which the sale of a patented device to be used by the customer for experimenta purposes or for inspiring him to improvements was not exempted from patent protection.

${ }^{10}$ BeckRS 2013, 01711.
} 
H.-R. Jaenichen and J. Pitz

pany itself was not capable of preparing the relevant test kits, this would lead to the experimental use exemption becoming void. Thus, if the contract was drafted accordingly, the customer's privileged experimental activities should be able to have a favorable effect on the supplier. The contract might include a recital of the specific experiments and a provision according to which the materials supplied must be exclusively used as objects of study. With contract language limiting the use of the supplied material to privileged experiments only, the production and distribution of the materials should likewise have to be considered as privileged use acts. According to the prevailing opinion in the literature, it is nevertheless not permitted to advertise and offer patent-protected test substances to an indefinite group of customers by merely stating "for experimental purposes." ${ }^{\prime 1}$ Based on the prevailing opinion in patent literature, production and supply of patent-protected antibodies are allowed.

\section{Bolar Provision}

The exemption regulated by $\$ 11$ No. 2b GPA provides that the effects of a granted patent do not extend to studies and trials, including their practical requirements, necessary for obtaining drug approval for the marketing of a drug within the EU or drug approval in a member state of the EU or abroad. This exemption is similar to the so-called Roche-Bolar (safe harbor) exemption in the United States. It is limited to research purposes for obtaining market approval for a pharmaceutical compound. However, within this range, its scope of exemption is broader than the exemption regulated by $\$ 11$ No. 2 GPA. In particular, this Bolar-type exemption is not limited to research on the subject matter of a protected product or process but also allows

\footnotetext{
${ }^{11}$ Cf. Chrocziel, Die Benutzung patentierter Erfindungen zu Versuchs- und Forschungszwecken, MIP-Schriftenreihe Bd. 67, Koln, 1986, 195; Straus, GRUR 1993, 308, 311; Chrocziel/ Hufnagel, Versuchsprivileg und Unterstützungshandlungen: Abgrenzungsfragen im, "Bermuda-Dreieck" der Doppelparagraphen 9, 10, 11 Nr. 2/2b GPA, Festschrift Mes, 2009 , p. 59 et seqq.
}

research with a patent-protected product or process. According to the prevailing opinion of scholars, the use of a patented research tool will therefore fall under the Bolar exemption of $\$ 11$ No. 2b GPA if the use of the tool is necessary for obtaining approval data or if it is explicitly required by the approval authority. ${ }^{12}$

The German Bolar provision is not limited to generics but also covers trial activities with innovative drugs for the purpose of obtaining regulatory approval.

Based on the above principles, Dr. Curly's clinical trials are allowed by the Bolar exemption as long as the trials are necessary for obtaining data required in the approval proceedings. Studies that are undertaken with a view to filing applications for marketing authorizations outside the EU also fall under the scope of the Bolar exemption in Germany. Therefore, it is not detrimental for the Bolar privilege in Germany that Dr. Curly seeks pharmaceutical approval only for the United States and not for Europe.

As to Dr. Specific's pilot studies, it has to be noted that mere preclinical research with the aim of developing new pharmaceuticals is not covered by the Bolar exemption of $\$ 11$ No. $2 \mathrm{~b}$ GPA. Contrary to the legal situation in the United States, ${ }^{13}$ it is not sufficient, according to German

\footnotetext{
${ }^{12} \mathrm{Cf}$. Holzapfel, Die patentrechtliche Zulässigkeit der Benutzung von Forschungswerkzeugen, GRUR 2006, 11 set seqq; von Meibom/vom Feld, Durchgriffsansprüche (ReachThrough-Ansprüche) bei Patenten für Forschungswerkzeuge, Festschrift für Kurt Bartenbach (2005), pp. 385, 398.

${ }^{13}$ In Merck KGaA v. Integra Life Sciences I, Ltd., the Court of Appeal of the Federal Circuit (CAFC) decided on July 27, 2007, the extent of the Bolar exemption. In said case, Merck had used a specific peptide sequence in experiments for researching angiogenesis inhibition, on which peptide Integra held patent rights. These experiments were directed to determining whether various peptides covered by the patent were suitable for pharmaceutical use. The CAFC held that the safe harbor exemption did not apply on the grounds that the experiments performed were not reasonably related to the development and submission of information to the FDA and that some of the data obtained were not used for approval purposes. The Supreme Court reversed the judgment of the CAFC and remanded the case for a renewed decision. According to the findings of the Supreme Court, it is sufficient if the experiments reasonably relate to FDA approval proceedings. Thus, the preclinical trials were covered by the Bolar exemption.
} 
Patents and Research Exemption in the EU

patent law, that the experiments merely have a peripheral reference to the pharmaceutical approval proceedings. Rather, it is necessary that the studies and trials are necessary for directly obtaining data required in the approval proceedings. However, the exemption of preclinical research having the purpose of determining the suitability of substances for the development of new pharmaceuticals should generally be covered by the research exemption, according to $\$ 11$ No. 2 GPA (see "Research Privilege” above). As a consequence, Dr. Specific's activities are covered by the experimental use exemption.

\section{THE SITUATION IN OTHER MEMBER STATES OF THE EU}

\section{United Kingdom}

$\$ 60$ of the U.K. Patents Act (UKPA) defines direct and indirect infringement of patent rights and provides for certain exemption from infringement, which (like in Germany) have been modeled on the European Patent Convention.

\section{The U.K. Experimental Use Exemption}

An act that would constitute an infringement of a patent for an invention shall not do so if it is done for experimental purposes relating to the subject matter of the invention $(\$ 60(5)(\mathrm{b})$ UKPA).

In the Monsanto decision (Monsanto Co. v. Stauffer Chemical Co. (1985) (RPC 515)), which is still considered to be settled U.K. law, the court held that the U.K. "experimental use" exemption covers activities that seek to generate genuinely new information but not those that seek to verify existing knowledge. For example, in the Monsanto case, it was held that field trials carried out in order to (1) discover something unknown, (2) test a hypothesis, (3) find out whether something that is known to work in specific conditions would work in different conditions, or (4) see if the experimenter could manufacture commercially in accordance with the patent could "fairly be regarded as experiments." However, trials to demonstrate to a third party or to amass information to satisfy a third party such as a regulatory body or customer that a product works as its maker claims are not to be regarded as acts done for experimental purposes. The key question in each case is whether or not the studies or tests have been carried out to advance scientific knowledge and determine something new. If so, then they should be exempt under $\$ 60(5)$ (b) UKPA insofar as they relate to the subject matter of the invention. According to the Monsanto decision, this would cover:

experiments directed to the patented invention as such, experiments such as testing whether a patented product can be made, or a patented article made to work, as described in the patent specification, or experiments to see whether the patented invention can be improved or testing the effect of the modification in some particular to see whether it is an improvement or not. But the limitation would...exclude from the exemption... use of a patented article or process in experiments to test or evaluate some other product or process. ${ }^{14}$

\section{The U.K. Bolar Exemption}

An act which would constitute an infringement of a patent for an invention shall not do so if it consists of an act done in conducting a study, test, or trial which is required for the purpose of regulatory approval of generic medicinal products ( $\$ 60(5)(\mathrm{i})$ UKPA).

In line with the relatively restrictive approach to the experimental use exemption explained above, the implementation of Directive 2004/27/EC (amending Directive 2001/83/ EC) in the United Kingdom through $\$ 60$ (5)(i) UKPA is narrow, applying only to studies, tests, or trials conducted in the context of abridged, hybrid, and biosimilar applications for regulatory approval of generic or similar biological medicinal products to an approved patented product.

In particular, it would not appear to extend to phase 1, 2, and 3 clinical trials of new chemical entities, in respect of which a defense must still be sought under the experimental use defense under $\$ 60(5)$ (b) UKPA.

\footnotetext{
${ }^{14}$ Monsanto Co. v. Stauffer Chemical Co. (1985) RPC15.
} 
H.-R. Jaenichen and J. Pitz

Directive 2001/83/EC applies to medicinal products for human use intended to be placed on the market in member states (article 2) and the United Kingdom. The Bolar exemption would therefore seem to apply regardless of whether the trial is conducted in the United Kingdom with the intention of applying for marketing authorization in the United Kingdom or in any other European country.

The questions of whether the use of a patent-protected product as a research tool would be protected under the U.K. Bolar exemption as long as it is necessary for obtaining data necessary for a marketing approval, as appears to be the case in Germany, has not been considered by the English courts.

In 2012, the U.K. government initiated a consultation exercise to consider whether the existing narrow Bolar-like exemption should be expanded. The results of that consultation led to the conclusion that $\$ 60(5)$ of the Patents Act 1977 will be amended to exempt all activities involved in preparing or running clinical or field trials with innovative pharmaceuticals that are conducted for the purpose of obtaining regulatory approval in any country. It is foreseen that the amendments to the law will come into force by a Legislative Reform Order on October $1,2014$.

\section{France}

\section{The Experimental Use Exemption in France}

According to article L. 613-5 of the French Code of Intellectual Property, the rights afforded by the patent shall not extend to acts done for experimental purposes relating to the subject matter of the patented invention, to studies and trials required with a view to obtain a marketing authorization for a medicinal product, as well as to acts necessary for their performance and for obtaining the authorization.

The Paris First Instance Court in 2001 ruled that phase 3 clinical trials performed on a medicinal product that is not a generic product were covered by Paragraph b. ${ }^{15}$ For this exemp-

${ }^{15}$ TGI Paris, February 20, 2001. tion, a restrictive interpretation should be given, and this rule cannot apply to acts with mere business purposes. As in Germany, the experiments must be conducted on the patented invention and not with the patented invention, that is to say, where the patented invention is used as a tool.

\section{The French Bolar Exemption}

According to the French Bolar exemption, the privileged acts must be necessary for the performance of clinical trials as required by the regulatory authorities. The trials must be required with a view to obtaining a marketing authorization for a medicinal product.

French law does not specify whether the marketing authorization should be French. Some authors consider that the exemption also covers the trials performed to obtain a foreign marketing authorization, but it is not obvious that French courts would follow such a position.

As with the German system, the French legislators did not seem to limit the exemption to generic products. However, there is still no relevant case law on this issue. Some authors consider that the legislators did so on purpose and that the exemption should not be limited to generics. ${ }^{16}$

\section{Spain}

In 2006, the so-called Bolar clause was included within the scope of the experimental use exemption in Spain. According to Article 52, paragraph (b) of the 11/1986 Spanish Patent Act, the scope of protection conferred by the patent does not cover acts made for an experimental purpose whose object consists of the patented invention. Such acts "include studies and tests carried out with the aim of obtaining a marketing authorization of generic drugs in or outside Spain, along with the necessary practical

${ }^{16} \mathrm{~J}$. Armengaud and E. Berthet-Maillol, "La loi du 26 février 2007 transposant la Directive 2004/27 CE ou le coup de pouce donné aux génériques," Propriétés intellectuelles, April 2007, no. 23 
Patents and Research Exemption in the EU

requirements, including the preparation, obtaining, and use of the active principle for these purposes."

Italy

\section{The Experimental Use Exemption in Italy}

Under Article 68 of the Italian Code of Industrial Property, the exclusive right granted by a patent does not extend, irrespective of the object of the invention, to acts carried out in an experimental manner; to studies and experiments aimed at obtaining, also in foreign countries, an authorization for the placing on the market of a drug; or to the consequent practical fulfillments thereof, including the preparation and use of pharmacologically active raw materials strictly necessary for such purpose.

According to the experimental use exemption, it is allowed to use patented products to the extent that the research work is finalized to improve the patented invention. The mere application of the patented product is instead not permitted. The difference between improving and applying a patented product is determined by observing the type of the experiments actually performed by the unauthorized patent user. The purpose of said experiments is irrelevant.

\section{The Italian Bolar Exemption}

With regard to the implementation of the Bolar provision in Italy, studies and experiments aimed at obtaining, also in foreign countries, an authorization for the placing on the market of a drug are permitted. The Bolar exemption includes principally the preparation and use of pharmacologically active raw materials strictly necessary for test purposes.

By using the expression in the Bolar provision "also in foreign countries," Italian law does not distinguish among an Italian authorization, an authorization in the EU, and an authorization outside the EU.

Furthermore, as in the German and French systems, the Italian legislature also does not limit the exemption to generic products.

\section{The Netherlands}

\section{The Dutch Research Exemption}

In The Netherlands, the research exemption has been laid down in Article 53(3) of the Dutch Patent Act. This article provides that acts solely serving for research on the patented subject matter, including the product obtained directly as a result of using the patented process, do not infringe the exclusive right of the patent owner.

Dutch courts apply the research exemption restrictively. Only purely scientific acts that exclusively serve for investigating the patented invention are privileged. Market research or largescale manufacture is not allowed.

\section{The Dutch Bolar Provision}

The Bolar provision, which is supplementary to the research exemption, has been implemented in Article 53(4) of the Dutch Patent Act. This article provides that conducting the necessary studies, tests, and trials within the context of obtaining a market authorization for a generic medicinal product (hybrid generics and biosimilars included) shall not be regarded as contrary to patent rights or to supplementary protection certificates for medicinal products. The Dutch Bolar provision is limited to generics.

Both bioavailability studies, which are required within the context of true generic applications, and preclinical tests and clinical trials, which are required within the context of hybrid applications and biosimilar applications, are permitted to be performed.

\section{SUMMARY}

This overview on the legal requirements, the extent, and the limitations of experimental use exemptions in the EU demonstrates that patent law allows sufficient room for research activities to promote innovation. This is not only true for tests and experiments to uncover new knowledge about patent-protected products, substances (and their supply), methods, and devices, but also holds true for clinical trials conducted with the purpose of registering and marketing medicinal products. 


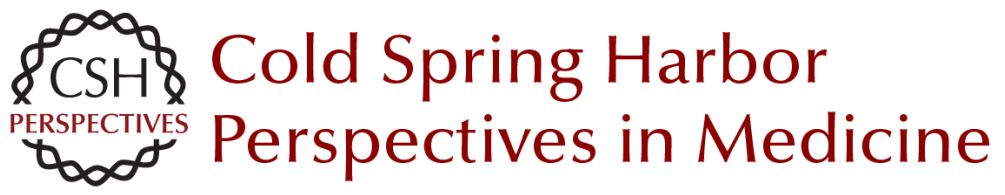

\section{Research Exemption/Experimental Use in the European Union: Patents Do Not Block the Progress of Science}

Hans-Rainer Jaenichen and Johann Pitz

Cold Spring Harb Perspect Med 2015; doi: 10.1101/cshperspect.a020941 originally published online November 6, 2014

Subject Collection Intellectual Property in Molecular Medicine

Patentability of Stem Cells in the United States Sarah E. Fendrick and Donald L. Zuhn, Jr.

Inventorship and Authorship

Antoinette F. Konski and Linda X. Wu

The Patentability of Stem Cells in Australia Jenny Petering and Prue Cowin

Impact of America Invents Act on Biotech

Intellectual Property

Amanda Murphy, Michael Stramiello, Jonathan Stroud, et al.

Introduction to Intellectual Property: A U.S.

Perspective

Amanda Murphy, Michael Stramiello, Stacy Lewis, et al.

The Role of Regulatory Agencies and Intellectual

Property: Part I

Kevin E. Noonan

Canada's Patented Medicines (Notice of

Compliance) Proceedings and Intellectual

Property

Henry Bian and Conor McCourt

Patentability of Genes: A European Union

Perspective

Paul Cole
The Impact of Myriad on the Future Development and Commercialization of DNA-Based Therapies and Diagnostics

Michele Wales and Eddie Cartier

Protecting Traditional Knowledge Related to

Biological Resources: Is Scientific Research

Going to Become More Bureaucratized?

Prashant Reddy and Malathi Lakshmikumaran

Protecting Trade Secrets in Canada Noel Courage and Janice Calzavara

Inherent Anticipation in the Pharmaceutical and

Biotechnology Industries

Michael Goldman, Georgia Evans and Andrew Zappia

The Role of Regulatory Agencies and Intellectual

Property: Part II Kevin E. Noonan

Baseball Bats and Chocolate Chip Cookies: The Judicial Treatment of DNA in the Myriad Genetics Litigation Ian Binnie and Vanessa Park-Thompson

The Impact of Myriad and Mayo: Will

Advancements in the Biological Sciences Be

Spurred or Disincentivized? (Or Was Biotech

Patenting Not Complicated Enough?) Jennifer Gordon

Trade Secrets in Life Science and Pharmaceutical Companies

Tara Nealey, Ronald M. Daignault and Yu Cai

For additional articles in this collection, see http://perspectivesinmedicine.cshlp.org/cgi/collection/ 